\title{
CRÓNIC A
}

\section{Homenaje a S.S. Juan Pablo II}

La Facultad de Teología de la Pontificia Universidad Católica de Chile ha querido rendir homenaje a S. S. Juan Pablo II, en ocasión de su muerte. La oportunidad ha sido ofrecida por la Vicerrectoría de Comunicasiones y Extensión durante el lanzamiento del libro Un Vigía de los Tiempos. Diez miradas universitarias al pensamiento de Juan Pablo II, de varios académicos de nuestra Universidad.

El homenaje consistió en tres breves exposiciones acerca de puntos específicos de la teología del Papa Juan Pablo II. Intervinieron el Prof. Juan Noemi C., Director de Postgrado; el Padre Rodrigo Polanco F., Profesor de nuestra Facultad y Rector del Seminario Pontificio, y el Padre Samuel Fernández E., Decano de la Facultad.

\section{LA ENCARNACIÓN COMO FUNDAMENTO TEOLÓGICO DE LA DIGNI- DAD DE LA PERSONA HUMANA}

Me atrevo a proponerles una breve reflexión teológica que quisiera prolongar el planteo de un apreciado colega. Samuel Fernández ha escrito recientemente en un periódico que "la principal enseñanza de Juan Pablo II" consiste en afirmar el valor de toda y cada vida humana -en sus términos-: "una persona no vale por su eficiencia, su productividad... cada persona vale por lo que es". Ahora bien, la pregunta teológica que surge al detectar como principal enseñanza del magisterio de Juan Pablo II esta premisa inmediatamente antropológica es la de indagar sobre la fundamentación, las razones que la sostienen. No se olviden que la teología no consiste en reiterar o repetir lo que se cree, sino en pensarlo. La cogitatio fidei es reconocida como una definición clásica de la teología cristiana. Esta definición se apoya en la constatación agustiniana: el creer no exime, sino que supone e incentiva el pensar. Requerimiento que se hace todavía más imperioso en un contexto cultural como el actual que privilegia la eficiencia y la productividad y para el cual la enseñanza del Papa no tiene nada de obvia.

Lo que se pretende por lo tanto es esbozar el fundamento de esta enseñanza del magisterio de Juan Pablo II que - a mi parecer con razón-Samuel Fernández recoge como principal.

Ya en su primera encíclica de 1979 Juan Pablo II señala, como radical fundamento teológico de la valía ontológica de cada ser humano, la encarnación de Dios en Jesús. En Redemptor Hominis 8 se cita el texto del Concilio Vaticano II (Gaudium et Spes 22): "Realmente el misterio del hombre solo se esclarece en el misterio del Verbo encarnado... Cristo manifiesta plenamente el hombre al propio hombre y le descubre la grandeza de su vocación... pues Él mismo, el Hijo de Dios con su encarnación, se ha unido en cierto modo con todo hombre". Más adelante, en R.H. 
13, se reitera la citación del mismo texto conciliar y explica: "No se trata del hombre abstracto sino real, del hombre concreto, histórico. Se trata de cada hombre porque cada uno ha sido comprendido en el misterio de la redención y con cada uno se ha unido Cristo para siempre".

Ni el Vaticano II ni Juan Pablo II innovan al referirse a la encarnación como fundamento teológico decisivo de la dignidad de toda y cada persona humana. Así por ejemplo en el siglo IX el Sínodo de Quiercy refuta la teoría de una doble predestinación recurriendo al mismo argumento: “así como no hay, hubo o habrá hombre alguno cuya naturaleza no fuera asumida en él, así no hay, hubo o habrá hombre alguno por quien no haya sido y padecido Cristo Jesús Señor nuestro" (D.H. 624). El misterio de la encarnación no concierne y afecta de modo exclusivo y excluyente a la naturaleza humana de Jesucristo, sino que incluye la de todos los seres humanos: "Filius Dei, incarnatione sua cum omni homini quodammodo se univit" ("El Hijo de Dios con su encarnación se ha unido en cierto modo con cada hombre") como afirma el Vaticano II y reitera Juan Pablo II. En este mismo sentido Juan XXIII habla de "la sagrada dignidad de la persona humana" (Mater et magistra 220) "en cuanto es sociable por naturaleza y ha sido elevada a un orden sobrenatural" (Mater el magistra 219).

Se recoge así una constante del judeocristianismo que postula una relación íntima e indisoluble entre teología y antropología. A la intransigencia del monoteísmo yahvista - "yo soy Yahvé tu Dios"- es correlativa una normatividad que supone un paradigma antropológico (Ex 20, 1 ss; Dt 5, 6 ss). Análogamente, el evangelio de Jesucristo no se plantea como abstracta teoría acerca de Dios, sino que comporta una definición antropológica fundamental que traduce un acontecimiento decisivo: todo hombre ha sido reconciliado y justificado con Dios en Jesús (Rm 5, 15-19). De esta manera, por una parte, se universaliza el planteo veterotestamentario en la medida que se postula a Dios como fin irreemplazable de todo hombre y no solo de Israel. Por otra parte, se profundiza en la raíz divina y humana que comporta este designio salvador de Dios. Este va más allá de lo que pueda ser la justicia, la calidad moral de cada individuo y arranca del mismo misterio trinitario como designio para el hombre.

Así lo reseña finamente A. Meis en su contribución al libro que hoy se presenta y que titula "El misterio trinitario en el pensamiento de Juan Pablo II", cuando concluye su documentado y penetrante estudio: "Impresiona la atención que presta el Papa al hombre concreto y su situación en el mundo. Él inserta su discurso en la problemática compleja del mundo actual y la esclarece desde el misterio trinitario. A ello obedece su insistencia en que el Verbo de Dios 'baja' a lo más profundo de la realidad humana, para transformar su vejez gastada en novedad inaudita por el misterio de la Encarnación, que así se torna misterio de redención... El eje articulador de la comprensión papal del misterio trinitario es, por consiguiente, Cristo Dios hecho hombre, quien, como consubstancial del Padre, no solo abre al hombre el acceso a la realidad de Dios, sino que posibilita que el hombre sea configurado a Él en lo más propio de su ser, es decir, por el misterio inefable de la filiación... Sin duda, el Padre es el origen último del misterio inefable de amor en el pensamiento de Juan Pablo II. Pero nuevamente en atención al hombre contemporáneo necesitado y deshecho por una vida, hasta malintencionada, el Papa articula su comprensión trinitaria en respuesta a esta situación compleja, más parecida a la del hijo pródigo 
que a la criatura salida en todo su esplendor de las manos del Creador, con una capacidad de memoria, inteligencia y voluntad, que Agustín descubre como imagen propiamente tal de la Trinidad, una verdad innegable, que el Papa no integra en su teología trinitaria, prefiriendo pensarla como "misterio de misericordia'" (p.125).

Tendríamos pues que la enseñanza papal -en continuidad con una constante de la tradición judeocristiana- no nos confronta a un optimismo prometeico en la eficacia del esfuerzo, sino a un realismo antropológico que se funda ontológicamente en la sobreabundancia del designio salvador de Dios en Jesús. Al encarnarse en Jesús, Dios, por así decirlo, se apropia de toda la humanidad, sella ontológicamente una alianza con todos y cada uno de los miembros de la especie humana. Esta apropiación ontológica no comporta, sin embargo, una confusión entre Dios y el hombre, sino que así como en la persona de Jesús no se mezclan su naturaleza humana y divina, así en nosotros el designio salvífico de Dios nos reconfirma, por una parte, en nuestra finitud humana $y$, por otra, la abre o proyecta a Dios como meta plenificadora.

JuAn NoEmi CALLEJAS

Profesor de la Facultad de Teología

\section{EL PAPA JUAN PABLO II, UN PASTOR QUE AMÓ Y SE ENTREGÓ POR LA IGLESIA}

El pensamiento del Papa Juan Pablo II es muy amplio. De hecho, no hubo tema que quedara fuera. Esto no es una casualidad, ni se debe simplemente a lo largo de su pontificado. Mucho más hondamente, nace de una profunda comprensión de su misión como Pastor Universal, y sobre todo, como hombre de Iglesia. Además, se funda en una muy cuidada eclesiología, esto es, una comprensión de la Iglesia, iluminada desde su raíz por el pensamiento del Concilio Vaticano II, que como muchas veces él mismo lo dijo, marcó su vida. Se sentía con el deber de llevar adelante las grandes y auténticas intuiciones del Concilio. Así lo afirmaba en su primera encíclica -programática-Redemptor hominis: "Con esta elección, siguiendo el ejemplo de mi venerado Predecesor, deseo al igual que él expresar mi amor por la singular herencia dejada a la Iglesia por los Pontífices Juan XXIII y Pablo VI y al mismo tiempo mi personal disponibilidad a desarrollarla con la ayuda de Dios" (2).

Por otra parte, es sabido que esta encíclica orientó toda su misión y magisterio. Allí, a comienzos de 1979, propone a Cristo, el Redentor del hombre, como el centro del cosmos y de la historia. Sin embargo, aparece también la Iglesia, como un tertium quid, que no siendo un fin en sí misma, permite la auténtica comunión entre el Redentor y el hombre, todo hombre. Quisiera entonces hacer algunos alcances acerca de las principales ideas eclesiológicas del Papa Juan Pablo II, que apuntan al desarrollo del hombre.

Como acabamos de decir, en su encíclica programática sienta las bases también de lo que fue luego todo su magisterio eclesiológico. Así comenzaba: "El Redentor del hombre, Jesucristo, es el centro del cosmos y de la historia. A Él se vuelven mi pensamiento y mi corazón en esta hora solemne que está viviendo la Iglesia y la 
entera familia humana contemporánea" (1). La pregunta es ¿y de dónde nace la Iglesia?: de Cristo. Esa es su riqueza y su grandeza. Pero a la vez le indica su finalidad. Afirma el Papa en RH 7, al inicio del segundo capítulo. El primero propiamente teológico: "Debemos tender constantemente a Aquel 'que es la cabeza', a Aquel 'de quien todo procede y para quien somos nosotros', a Aquel que es al mismo tiempo 'el camino, la verdad' y 'la resurrección y la vida'... En Él 'están escondidos todos los tesoros de la sabiduría y de la ciencia', y la Iglesia es su Cuerpo. La Iglesia es en Cristo como un 'sacramento, o signo e instrumento de la íntima unión con Dios y de la unidad de todo el género humano’ (LG 1) y de esto es Él la fuente. ¡Él mismo! ¡Él, el Redentor! La Iglesia no cesa de escuchar sus palabras, las vuelve a leer continuamente, reconstruye con la máxima devoción todo detalle particular de su vida".

Pero esta unión con Cristo no es simplemente intencional, o moral, es mucho más profundamente, de naturaleza sacramental. Por eso no es de extrañar que al culminar su pontificado llame a un año eucarístico y escriba su última encíclica: Ecclesia de Eucharistia. Es la culminación del programa inicial: Cristo, el Redentor del hombre, sigue presente con su fuerza salvadora en su Iglesia que nace de la Eucaristía, como perpetuación del sacrificio redentor del mismo Cristo.

Basándose en un número muy importante de LG (3) afirma en EE 21: "El Concilio Vaticano II ha recordado que la celebración eucarística es el centro del proceso de crecimiento de la Iglesia. En efecto, después de haber dicho que 'la Iglesia, o el reino de Cristo presente ya en misterio, crece visiblemente en el mundo por el poder de Dios', como queriendo responder a la pregunta: ¿Cómo crece?, añade: 'Cuantas veces se celebra en el altar el sacrificio de la cruz, en el que Cristo, nuestra Pascua, fue inmolado, se realiza la obra de nuestra redención. El sacramento del pan eucarístico significa y al mismo tiempo realiza la unidad de los creyentes, que forman un solo cuerpo en Cristo'. Hay un influjo causal de la Eucaristía en los orígenes mismos de la Iglesia... Análogamente a la alianza del Sinaí, sellada con el sacrificio y la aspersión con la sangre, los gestos y las palabras de Jesús en la Última Cena fundaron la nueva comunidad mesiánica, el Pueblo de la nueva Alianza... Desde aquel momento, y hasta al final de los siglos, la Iglesia se edifica a través de la comunión sacramental con el Hijo de Dios inmolado por nosotros: 'Haced esto en recuerdo mío... Cuantas veces la bebiereis, hacedlo en recuerdo mío' (1 Co 11, 24-25)".

La cruz constituye a la Iglesia. Sin embargo al hablar de la Pasión del Señor, el Papa, siguiendo la enseñanza conciliar, la relaciona fuertemente con la Eucaristía. Tan esencial como la cruz, pasa a ser ahora la Eucaristía, por ser precisamente permanencia del misterio pascual de Cristo en la cruz. Si la cruz ha realizado la salvación y como su fruto el Pueblo de la nueva Alianza, entonces si la Eucaristía es la perpetuación de la cruz, en consecuencia es también el fundamento perpetuo y originario de la Iglesia. Es la presencia constante de Cristo como Fundamentador de la Iglesia, además de haber sido su Origen y Fundador. La eucaristía es la perpetua actualización del sacrificio de Cristo y por eso su celebración hace crecer a la Iglesia y la mantiene siempre como una fuente desde la cual mana la Iglesia.

Pero también el Espíritu Construye la Iglesia. Afirma el Papa en RH 18: "La Iglesia se une con el Espíritu de Cristo, con el Espíritu Santo que el Redentor había 
prometido, que comunica constantemente y cuya venida, revelada el día de Pentecostés, perdura siempre. De este modo en los hombres se revelan las fuerzas del Espíritu, los dones del Espíritu, los frutos del Espíritu Santo. La Iglesia de nuestro tiempo parece repetir con fervor cada vez mayor y con santa insistencia: ¡Ven, Espíritu Santo! ¡Ven! ¡Ven! Esta invocación al Espíritu y por el Espíritu no es más que un constante introducirse en la plena dimensión del misterio de la Redención, en que Cristo unido al Padre y con todo hombre nos comunica continuamente el Espíritu que infunde en nosotros los sentimientos del Hijo y nos orienta al Padre".

Vemos entonces que el acontecimiento de Pentecostés es el que hace de la Iglesia aquel "misterio" de la presencia de Cristo como su cuerpo en medio del mundo. El Espíritu de Cristo vive en la Iglesia y en cada miembro como en un templo y los unifica a todos y los injerta a Cristo, como LG 4 había expresado, texto que está al origen del párrafo recién citado. El Espíritu ora en los hombres y da testimonio de que son hijos adoptivos. Da la vida y une a la Iglesia a través de la comunión y el servicio, con dones jerárquicos y carismáticos. La idea de unificación del pueblo de Dios está detrás de esta actuación del Espíritu. Como afirmaba Ireneo, el Espíritu renueva, rejuvenece y lleva a la Iglesia a la comunión perfecta con su esposo. Así pues, tal como la cruz permanece activa en la Eucaristía, Pentecostés permanece presente a través de los dones jerárquicos y carismáticos que recibe todo el Pueblo de Dios.

La Eucaristía y el Espíritu hacen de la Iglesia, sacramento. Y eso implica la misión. De ahí que en diciembre de 1990, el Papa escribe Redemptoris missio, podríamos decir, la carta magna de la eclesiología del Papa. En efecto, el Papa no escribe un documento llamado De Ecclesia, sino que su eclesiología es la misión. Y de hecho, en esta encíclica es donde más desarrolla su pensamiento con respecto a la Iglesia. Aunque, en realidad, la eclesiología del Papa es la suma de Redemptor hominis, Ecclesia de Eucharistia y Redemptoris missio.

Nuevamente, en Redemptoris missio, comienza con la afirmación de la centralidad de Cristo. Afirma: "La salvación no puede venir más que de Jesucristo... La revelación de Dios se hace definitiva y completa por medio de su Hijo unigénito: 'Muchas veces y de muchos modos habló Dios en el pasado a nuestros Padres por medio de los Profetas; en estos últimos tiempos nos ha hablado por medio del Hijo a quien instituyó heredero de todo, por quien también hizo los mundos'. En esta Palabra definitiva de su revelación, Dios se ha dado a conocer del modo más completo; ha dicho a la humanidad quién es. Esta autorrevelación definitiva de Dios es el motivo fundamental por el que la Iglesia es misionera por naturaleza. Ella no puede dejar de proclamar el Evangelio, es decir, la plenitud de la verdad que Dios nos ha dado a conocer sobre sí mismo" (RM 5).

Pero la Iglesia cumple su misión volcándose al hombre: El camino de la Iglesia es el hombre. Siguiendo GS 22, el Papa afirma su convicción en RH 13 y 14: " Mediante la encarnación el Hijo de Dios se ha unido en cierto modo a todo hombre'. La Iglesia divisa por tanto su cometido fundamental en lograr que tal unión pueda actuarse y renovarse continuamente. La Iglesia desea servir a este único fin: que todo hombre pueda encontrar a Cristo, para que Cristo pueda recorrer con cada uno el camino de la vida, con la potencia de la verdad acerca del hombre y del mundo, contenida en el misterio de la Encarnación y de la Redención, con la potencia del amor que irradia de ella... Jesucristo es el camino principal de la Iglesia... 
La Iglesia, en consideración de Cristo y en razón del misterio, que constituye la vida de la Iglesia misma, no puede permanecer insensible a todo lo que sirve al verdadero bien del hombre, como tampoco puede permanecer indiferente a lo que lo amenaza... Aquí se trata por tanto del hombre en toda su verdad, en su plena dimensión. No se trata del hombre 'abstracto' 'sino real, del hombre 'concreto', 'histórico'. Se trata de 'cada' hombre, porque cada uno ha sido comprendido en el misterio de la Redención y con cada uno se ha unido Cristo, para siempre, por medio de este ministerio... Este hombre es el camino de la Iglesia".

Se da entonces un hermoso círculo: Cristo es el Redentor, desde el cual nace todo y hacia el cual tiende todo. Pero ese Cristo ha quedado presente en su Iglesia, que como tal, es necesaria para la salvación; indispensable en cuanto actualización de Cristo. Es necesaria, en cuanto 'relativa', esto es, que muestra a Otro, al Único. Esta Iglesia es necesaria porque es presencia de Cristo, a través de la Eucaristía y del Espíritu. Pero esta Iglesia está totalmente volcada al hombre, como el mismo Cristo lo está. Y toda su función está en llevar a todo hombre y mujer a Cristo. La Iglesia entonces no es fin en sí misma, sino camino del hombre a Cristo.

Pero -y esto es un aporte fundamental del Papa Juan Pablo II- no se oponen humanidad e Iglesia, sino que muy por el contrario, se complementan y se necesitan. La Iglesia es la humanidad en Cristo. El Papa, con su vida y con su magisterio, siguiendo las huellas de GS, insistió incansablemente en que el mundo necesita de la Iglesia, como también la Iglesia necesita de un adecuado diálogo y comprensión del mundo para cumplir cabalmente su misión.

De ahí que se puede comprender muy bien esta aparente paradoja del Papa Juan Pablo II: un hombre fuertemente claro en su fe y en la verdad de la Iglesia, y un Papa claramente volcado hacia el mundo y sus necesidades. Porque el Papa había logrado la síntesis: la Iglesia es el núcleo articulador de la comunión del hombre con Cristo.

Tal vez por eso en su multitudinario funeral se vio algo que no suele ser tan común: su figura no solo había sido relevante como pocas para la Iglesia, sino que el mismo mundo le reconoció su aporte y le tributó su homenaje. Estaban diciendo, todavía sin saberlo, que Cristo es 'el centro del cosmos y la historia', y que la Iglesia, es decir, los creyentes en Cristo, y en este caso particular uno de su fieles, el más visible, es el misterio del hombre que se ha hecho hijo de Dios, filiación que todos anhelan y buscan, aún sin saberlo.

PADRE RODRIGO POLANCO F. Rector del Seminario Pontificio

\section{CRISTO REDENTOR DEL HOMBRE, DE TODOS LOS HOMBRES Y DE TODO EL HOMBRE}

Entre las muchas cosas que sorprende del pontificado de Juan Pablo II es la amplitud de su magisterio. No solo por la abundancia de sus documentos -se ha hablado de decenas de miles de páginas-, sino también por la amplitud de los temas abordados.

Algunos se desconciertan al ver que este hombre tan interesado por la marcha del mundo, por la paz y por el desarrollo auténtico de las naciones, haya convocado 
un año del Rosario y un año de la Eucaristía. Y, por el contrario, para otros, es llamativo que este hombre tan profundamente religioso, caracterizado por su profunda vida de oración y su filial pertenencia a María, se haya internado en temas que parecen tan seculares, iluminado por su propia experiencia como obrero, vivida en condiciones sociales dificilísimas. Malamente alguno ha dicho que el Papa 'fue más allá del ámbito religioso’ ¿ ¿Cómo explicar esta tensión? ¿Cómo armonizar el espíritu religioso del Santo Padre con sus preocupaciones sociales? Otros se preguntan ‘qué prima en la mente del Papa?' e intentan establecer la prioridad de una de sus dimensiones por sobre las demás, sin ser capaces de captar la unidad de estas diversas preocupaciones. Una relectura de su encíclica programática, la Redemptor hominis, nos ofrece una clave de solución. Dada la brevedad del espacio disponible, lo más adecuado será desarrollar un único aspecto de esta Encíclica.

\section{Cristología y antropología}

La teología de los dos Adanes, iniciada por San Pablo y desarrollada de modo magistral en la Gaudium et Spes, del Vaticano II, la podemos considerar una de las claves para comprender la amplitud de miras del Santo Padre.

Pablo, en su carta a los romanos, declara que Adán 'era figura del que había de venir' (cf. 5,14). La afirmación nos sorprende, dado que la manifestación de Jesucristo es posterior a la de Adán. Estamos habituados a pensar que Cristo se hizo semejante a Adán, y que, por tanto, Cristo es copia del primer hombre. Pero la realidad es otra: el Adán original es Cristo, y una copia de Él es el Adán que pecó. Estas reflexiones, que podrían parecer tan teóricas, encierran un contenido de una gran trascendencia, aun en ámbito práctico. Lo que está detrás de la teología del Apóstol es que la verdadera humanidad se encuentra en Cristo y que en Adán encontramos la humanidad, pero la humanidad deformada por el pecado.

Esta convicción fue espléndidamente expresada por el Concilio Vaticano II en la Gaudium et Spes 22: "Tan solo en el misterio del Verbo Encarnado se aclara verdaderamente el misterio del hombre... Cristo, el nuevo Adán... manifiesta plenamente el hombre al hombre". De este modo, la cumbre de la vida humana se alcanza en Cristo.

De acuerdo a lo anterior, la auténtica humanidad no se encuentra en el pecador, sino en Cristo. Asemejarse a Cristo no significa renunciar a ser humano, para transformarse en algo como un ángel o en alguna cosa parecida. No, asemejarse a Cristo significa humanizarse; asemejarse a Cristo provoca un crecimiento en humanidad. En definitiva, somos verdaderamente hombres en la medida en que estamos en comunión con Cristo (1).

Por lo tanto, no hay contradicción entre Cristo y el ser humano. Dios no es adversario del hombre, sino su modelo primordial y su meta definitiva. Cristo es el único camino para la auténtica realización humana. Y, por ello, no es necesario rechazar nada humano para ser santo. Al contrario, es el pecado lo que nos obliga a

(1) Esta comunión se da de muchas maneras, incluso fuera de los límites visibles de la Iglesia, pero eso es ya otro tema. 
negar nuestra verdadera humanidad; el pecado deshumaniza, la santidad humaniza. Por ello, Cristo es más hombre que el Adán herido por el pecado.

De este modo se comprueba el carácter humanizador de la preocupación 'religiosa' del Papa; y, por otra parte, se manifiesta el carácter religioso de las preocupaciones aparentemente 'seculares' del Santo Padre.

\section{Justificación religiosa de la preocupación secular}

La preocupación por el hombre tiene una raíz religiosa: "La Iglesia, en consideración de Cristo y en razón del misterio, que constituye la vida de la Iglesia misma, no puede permanecer insensible a todo lo que sirve al verdadero bien del hombre, como tampoco puede permanecer indiferente a lo que lo amenaza" (RH 13). Esta contundente enseñanza de la Redemptor hominis fue repetida por el Santo Padre en su histórico viaje a Cuba (2). El texto es muy explícito: la búsqueda del bien del hombre forma parte de la misión de la Iglesia.

La Iglesia, cuando se preocupa del bien del hombre, está cumpliendo su propia misión, puesto que, a partir de la Encarnación, Cristo se ha unido en cierto modo con cada hombre. Por ello, el cristiano puede decir con el poeta latino Terencio: "Soy hombre, y nada humano me es ajeno".

"La Iglesia -insiste el Papa-, que está animada por la fe escatológica, considera esta solicitud por el hombre, por su humanidad, por el futuro de los hombres sobre la tierra y, consiguientemente, también por la orientación de todo el desarrollo y del progreso, como un elemento esencial de su misión, indisolublemente unido con ella. Y encuentra el principio de esta solicitud en Jesucristo mismo, como atestiguan los Evangelios. Y por esta razón desea acrecentarla continuamente en Él, "redescubriendo "la situación del hombre en el mundo contemporáneo, según los más importantes signos de nuestro tiempo” (RH 15).

La preocupación social de la Iglesia no es, entonces, algo periférico o secundario; mucho menos es una estrategia de proselitismo en un mundo secularizado. Es una exigencia del misterio de Cristo. La misma existencia terrena de Jesús lo manifiesta: sus milagros de curación muestran su voluntad de restaurar en el hombre la bendición original del Génesis: "Y vio Dios todo lo que había hecho, y todo estaba muy bien" (Gn 1,31), al tiempo que los testigos de la actividad sanadora de Jesús: "Todo lo ha hecho bien, hace oír a los sordos y hablar a los mudos" (Mc 3,37). La sanación corporal es signo de la renovación en el hombre de la bendición original del Génesis que había sido oscurecida por el pecado. Y la sorprendente cercanía de Jesús hacia los pecadores, muestra que en Él se hace presente la cercanía de Dios que se revela como Abbá, es decir, como un Papá cercano y cariñoso. El bienestar integral del hombre y las nuevas relaciones fraternas que se establecen a partir de la revelación de Dios como Padre, son signo y realización de la bendición divina, es decir, muestran que la vida humana es una bendición. La preocupación social de la Iglesia mira, entonces, a esto: a manifestar que la vida humana es una bendición divina, $y$, por lo tanto, un sacramento de la vida eterna.

(2) Discurso del 25 de enero de 1998, a los Obispos cubanos, La Habana. 
Justificación secular de la preocupación religiosa

Durante la inauguración del curso en la Universidad Católica del Sacro Cuore, el 9 de noviembre del año 2000, el Papa afirmó que 'Cristo es el revelador de Dios y también el revelador del hombre'. Declarando, de este modo, que solo en Cristo la humanidad accede a su propia verdad.

La auténtica humanidad se alcanza solo en Cristo, el Verbo de Dios encarnado, que ha compartido nuestra propia humanidad: "Trabajó con manos de hombre, reflexionó con inteligencia de hombre, actuó con voluntad humana y amó con humano corazón”. Jesús, el Hijo de Dios, al nacer de María la Virgen, asumió toda la realidad humana, $\mathrm{y}$, por tanto, no hay verdadera vida humana, sino en comunión con Jesucristo.

De este modo se comprende la naturalidad con que Juan Pablo II ha abordado un abanico tan amplio de temas, sin herir la auténtica autonomía relativa de las realidades seculares, y opinando con verdadera autoridad sobre temas que aparentemente no son religiosos sino seculares.

En un Congreso Internacional de Teología, organizado por la Universidad Gregoriana, el Papa parafraseando algunas palabras de su predecesor, Pablo VI, afirmó: "el teólogo, en la medida en que permanece fiel a la revelación, se convierte también en experto del hombre y de su destino”. El que conoce a Cristo, conoce al hombre y su destino, y, por tanto, tiene una palabra iluminadora, y a veces también crítica, frente a los diversos modelos de desarrollo. Por ello, en la Redemptor hominis se pregunta: "Este progreso, cuyo autor es el hombre, ¿hace la vida del hombre sobre la tierra, en todos sus aspectos, 'más humana'?; ¿la hace más 'digna del hombre'?" (RH 15).

La verdad de Cristo ilumina la vida de cada ser humano. Por eso el Papa ha podido impulsar a la Iglesia, con tanta energía, a la tarea evangelizadora, convencido de que la auténtica evangelización no es una intromisión en una determinada cultura, puesto que Cristo no es un intruso en la naturaleza humana, sino su origen, su modelo y su meta.

La evangelización no es un 'agregado' al bienestar humano, ni es un 'artículo de lujo’ para quienes ya tienen resueltas sus necesidades básicas. La evangelización forma parte de las necesidades básicas del ser humano, de todo ser humano.

Así lo declara el Santo Padre en la XXXV Jornada Mundial de las Comunicaciones Sociales: "En todas las culturas y en todos los tiempos-ciertamente en medio de las transformaciones globales de hoy en día-las personas se hacen las mismas preguntas fundamentales sobre el sentido de la vida: ¿quién soy?, ¿de dónde vengo y adónde voy?, ¿por qué existe el mal?, ¿qué hay después de esta vida? (cf. Fides et Ratio, 1). Y en cualquier período, la Iglesia ofrece la única y definitiva respuesta satisfactoria a las preguntas más profundas del corazón humano; el mismo Jesucristo 'manifiesta plenamente el hombre al hombre y le descubre su altísima vocación' (Gaudium et Spes, 22). Por lo tanto, los cristianos no deben nunca permanecer callados, el Señor nos ha confiado la palabra de salvación que todo corazón humano anhela. El Evangelio ofrece la perla de gran valor que todos están buscando (cf. Mt 13,45-46)". 
Esta es la gran certeza que ha animado el Magisterio de Juan Pablo II, y es la gran certeza que debe animar nuestra actividad universitaria. A la luz de esta verdad, y comprendida de esta manera la evangelización, todo se debe subordinar a la comunión con Jesucristo. Impulsados por la convicción de que el Evangelio no es un obstáculo para el desarrollo del hombre, sino el único camino para acceder a la auténtica vida humana. La comunión con Cristo humaniza, por eso se justifica aun secularmente la evangelización.

Así, después de este recorrido por algunos puntos centrales de la Encíclica Redemptor hominis, se comprenden mejor las palabras con que nuestro querido Santo Padre inauguró su ministerio, ese ya lejano 22 de octubre de 1978:

“¡No tengáis miedo! ;Abrid, más aún, abrid de par en par las puertas a Cristo! Abrid, a su fuerza salvadora, los confines de los Estados, los sistemas económicos al igual que los políticos, los amplios campos de la cultura, de la civilización, del desarrollo. ¡No tengáis miedo! Cristo sabe lo que hay dentro del hombre. ¡Solo Él lo sabe!”.

Yendo a las consecuencias más concretas. En este complejo mundo, podemos integrar a Cristo en nuestra actividad universitaria con la convicción de que el Evangelio ofrece al hombre su plenitud, y, por ello, ¡no tengáis miedo!, la moral no es un obstáculo a la felicidad ni el dogma un impedimento a la investigación científica; ¡no tengáis miedo! la fe no nos impide pensar ni los mandamientos son obstáculo para amar; ;no tengáis miedo!, la Doctrina Social de la Iglesia no es un freno para el desarrollo ni la fidelidad al Evangelio obstaculiza la unidad del género humano... y se podría ampliar esta lista. De este modo, podemos acoger con confianza las palabras de Juan Pablo II: “¡No tengáis miedo! ¡Abrid, más aún, abrid de par en par las puertas a Cristo!”.

PADRe SAMUel Fernández E. Decano de la Facultad de Teología 